\title{
Effect of Mixed Treatment of Urea Fertilizer and Zeolite on Nitrous Oxide and Ammonia Emission in Upland Soil
}

\author{
Jun-Hong Park, Sang-Jo Park, Young-Jin Seo, Oh-Heun Kwon, Seong-Yong Choi, \\ So-Deuk Park, and Jang-Eok Kim ${ }^{1}$ * \\ GyeongSangBuk-Do Agriculture Research and Extention Services, Daegu 702-708, Korea \\ ${ }^{1}$ School of Applied Biosciences, Kyungpook National University, Daegu 702-701, Korea
}

(Received: March 27 2014, Revised: September 19 2014, Accepted: September 22 2014)

\begin{abstract}
Ammonia loss from urea significantly hinders efficient use of urea in agriculture. The level of nitrous oxide $\left(\mathrm{N}_{2} \mathrm{O}\right)$ a long-lived greenhouse gas in atmosphere has increased mainly due to anthropogenic source, especially application of nitrogen fertilizers. There are reports in the literature showing that the addition of zeolite to $\mathbf{N}$ sources can improve the nitrogen use efficiency. This study was conducted to evaluate nitrous oxide $\left(\mathrm{N}_{2} \mathrm{O}\right)$ and ammonia $\left(\mathrm{NH}_{3}\right)$ emission by mixed treatment of urea and zeolite in upland crop field. Urea fertilizer and zeolite were applied at different rates to study their effect on $\mathrm{N}_{2} \mathrm{O}$ emission during red pepper cultivation in upland soils. The $\mathrm{N}_{2} \mathrm{O}$ gas was collected by static closed chamber method and measured by gas chromatography. Ammonia concentration was analyzed by closed-dynamic air flow system method. The total $\mathrm{N}_{2} \mathrm{O}$ flux increased in proportion to the level of $\mathrm{N}$ application. Emission of $\mathrm{N}_{2} \mathrm{O}$ from the field increased from the plots applied with urea-zeolite mixture compared to urea alone. But urea-zeolite mixture treatment reduced about $30 \%$ of $\mathrm{NH}_{3}-\mathrm{N}$ volatilization amounts. These results showed that the application of urea and zeolite mixture had a positive influence on reduction of $\mathrm{NH}_{3}$ volatilization, but led to the increase in $\mathrm{N}_{2} \mathrm{O}$ emission in upland soils.
\end{abstract}

Key words: Nitrous oxide, Urea, Zeolite, Ammonia

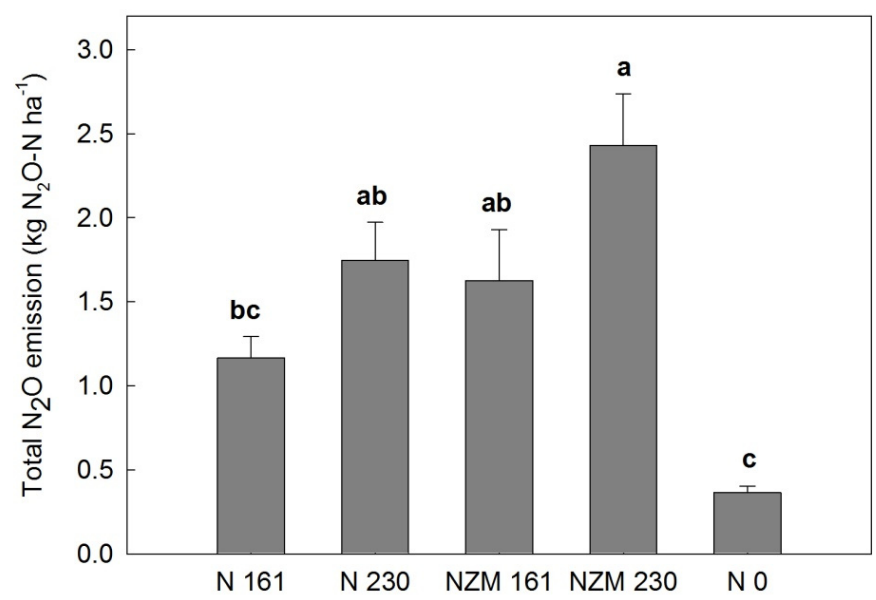

Total $\mathrm{N}_{2} \mathrm{O}$ emissions with nitrogen and zeolite treatments $\left(\mathrm{kg} \mathrm{ha}^{-1}\right)$ during red pepper cultivation. $\mathrm{NZM}$, nitrogen zeolite mixture. Enor bars indicate standard deviation. Treatments with same letter are not significantly different at the 0.05 probability level.

*Corresponding author : Phone: +82539505720, Fax:+82539507233, E-mail: jekim@knu.ac.kr

${ }^{\S}$ Acknowledgement: This research was supported by Rural Development Administration(PJ009315), Korea. 


\section{Introduction}

대표적인 온실가스의 하나인 아산화질소의 지구 온난화 잠재력은 이산화탄소와 비교하여 약 300 배 높은데, 대기의 아산화질소 농도는 매년 0.2 0.3\%씩 높아지고 있다 (Saggar et al., 2009). 세계 온실가스 중 아산화질소 배출량의 $64 \%$ 가 인간 활동에 의해 배출되며, 그 중 $92 \%$ 가 농업활동에 의 해 배출되는 것으로 보고하였다 (Duxbury et al., 1993). 우 리나라의 경우 농업부문에서 발생하는 아산화질소 배출량 은 약 6.9 백만 톤 $\mathrm{CO}_{2}-\mathrm{eq}$ 으로 우리나라 아산화질소 총 배 출량의 약 $36 \%$ 를 차지한다 (NIR, 2012).

농경지로부터 아산화질소 배출에 영향을 미치는 요인으 로는 질소 시비량, 토양 유기물 함량, 토양 산도, 토성, 작 물 종류, 영양원의 종류 등이 있다 (Stehfest, 2008). Kim et al. (2008)은 고추 재배지에서 아산화질소 배출에 영향을 미 치는 요인으로 식양토의 경우 무기태 질소 (51\%), 토양 온도 (26\%), 토양 수분함량 (23\%)이었으며, 사양토의 경우 토양 수분함량 $(39 \%)$, 토양 온도 $(36 \%)$, 무기태 질소 $(24 \%)$ 순이 었다고 하였다. 또한 사양토에서 아산화질소 배출량은 식양 토에 비해 74 82\% 적었고, 토양 수분장력이 $-50 \mathrm{kPa}$ 일 때 가 $-30 \mathrm{kPa}$ 인 경우보다 13 40\% 적었다고 하였다. 한편 Shin et al. (2003)은 콩 작기 중 아산화질소 배출량은 3.0 $4.7 \mathrm{~kg} \mathrm{~N} \mathrm{~N} \mathrm{ha}^{-1}$ 라고 하였는데, Kim et al. (2010)에 따르면 콩 재배지에서의 아산화질소 배출에 영향을 미치는 요인은 무 기태 질소 (66\%), 토양 수분 $(19 \%)$, 토양 온도 $(15 \%)$ 순이었다.

농업 생태계에서 유실된 질소는 환경오염을 증가시킬 수 있음에 따라 질소 이용 효율을 향상시키고 질소 유실을 감 소시키는 토양관리방안에 대한 연구가 꾸준히 진행되고 있 다 (Powlson et al., 2008). Zeolite는 높은 공극부피 (void volume), $150 \sim 250 \mathrm{cmol}_{\mathrm{c} \mathrm{kg}}{ }^{-1}$ 의 높은 양이온치환용량 (CEC) 을 가지고 있으며, $\mathrm{NH}_{4}^{+}, \mathrm{K}^{+}$등 양이온의 선택적 흡착 등의 특성을 가지고 있어 토양개량제, 퇴비첨가제, 살충제와 제 초제의 담체 등 다양한 용도로 농업에 이용되고 있다 (Clifton, 1987; Parham 1989). 또한 Zeolite는 토양에 처리하였을 때 무기태 질소의 흡착으로 유실을 감소시키고, 토양수분함량 을 증가시키며 작물생육을 증가시키는 것으로 보고하였고 (Ippolito et al., 2011), zeolite와 요소의 혼합시용에 따른 아산화질소의 배출량 변화와 암모니아의 초기 배출량에 대 한 연구는 없는 실정이다.

따라서 본 연구에서는 미사식양질 밭토양에서의 요소와 zeolite 혼합 처리시 아산화질소와 암모니아 배출에 미치는 영향을 평가하고자 수행하였다.

\section{Materials and Methods}

본 시험은 요소와 zeolite 혼합처리가 미사식양질 밭토양 에서의 아산화질소 배출에 미치는 영향을 조사하기 위하여 경 상북도농업기술원 시험포장 (북위 : $35^{\circ} 57^{\prime} 02^{\prime \prime}$, 경도 : $128^{\circ} 33^{\prime}$ $52^{\prime \prime}$, 해발고도 $50 \mathrm{~m}$ )에서 고추 (Capsicum annuum)를 대상으 로 수행하였다. 시험토양은 홍적대지에 분포된 식질계 적황색 토인 화동통 (fine, mixed, mesic family of Aquic Hapludalfs) 에 해당되며, $\mathrm{pH}$ 는 7.2 , 유기물은 $23 \mathrm{~g} \mathrm{~kg}^{-1}$, 유효인산 164 $\mathrm{mg} \mathrm{kg}{ }^{-1}$ 이었다 (Table 1).

시비는 농촌진흥청 작물별 시비처방기준 (NIAST, 2010) 에 따라 요소를 이용하여 고추 표준시비인 $230 \mathrm{~kg} \mathrm{~N} \mathrm{ha}{ }^{-1}$ 처리구, $30 \%$ 감비인 $161 \mathrm{~kg} \mathrm{~N} \mathrm{ha}^{-1}$ 처리구, $230 \mathrm{~kg} \mathrm{~N} \mathrm{ha}^{-1}$ 에 zeolite $500 \mathrm{~kg} \mathrm{ha}^{-1}$ 을 혼합 처리한 구, $161 \mathrm{~kg} \mathrm{ha}^{-1}$ 에 zeolite $350 \mathrm{~kg} \mathrm{ha}^{-1}$ 을 혼합 처리한 구, 요소 무시용구의 5

Table 1. Physico-chemical properties of upland soil used in experiment.

\begin{tabular}{|c|c|c|c|c|c|c|c|}
\hline \multirow{2}{*}{$\mathrm{pH}$} & \multirow{2}{*}{$\mathrm{OM}$} & \multirow{2}{*}{$\begin{array}{l}\text { Avail. } \\
\mathrm{P}_{2} \mathrm{O}_{5}\end{array}$} & \multicolumn{3}{|c|}{ Exch. cations } & \multirow{2}{*}{$\mathrm{EC}$} & \multirow{2}{*}{ Soil texture } \\
\hline & & & $\mathrm{K}$ & $\mathrm{Ca}$ & $\mathrm{Mg}$ & & \\
\hline$(1: 5)$ & $\mathrm{g} \mathrm{kg}^{-1}$ & $\mathrm{mg} \mathrm{kg}^{-1}$ & ------- & $\overline{\mathrm{ol}_{\mathrm{c}} \mathrm{k}}$ & -------- & $\mathrm{dS} \mathrm{m}^{-1}$ & \\
\hline 7.2 & 23 & 164 & 0.6 & 5.1 & 1.8 & 0.26 & $\mathrm{SiCL}$ \\
\hline
\end{tabular}

Table 2. Application rates of urea and zeolite in soil.

\begin{tabular}{cccc}
\hline \hline \multirow{2}{*}{ Treatment } & \multicolumn{3}{c}{ Application level } \\
\cline { 2 - 4 } & Urea & Zeolite & $\mathrm{P}_{2} \mathrm{O}_{5}-\mathrm{K}_{2} \mathrm{O}$ \\
\hline $\mathrm{N} 161$ & $-\mathrm{O}^{-1}$ & 0 & $112-149$ \\
$\mathrm{~N} 230$ & 500 & 0 & $112-149$ \\
$\mathrm{NZM} \mathrm{161 \dagger}$ & 350 & 350 & $112-149$ \\
$\mathrm{NZM} \mathrm{230}$ & 500 & 500 & $112-149$ \\
$\mathrm{~N} 0$ & 0 & 0 & $112-149$ \\
\hline
\end{tabular}

†NZM : Nitrogen-zeolite mixture 
Table 3. Chemical properties of zeolite.

\begin{tabular}{cccccccccc}
\hline \hline $\mathrm{SiO}_{2}$ & $\mathrm{Al}_{2} \mathrm{O}_{3}$ & $\mathrm{Fe}_{2} \mathrm{O}_{3}$ & $\mathrm{MgO}$ & $\mathrm{CaO}$ & $\mathrm{Na}_{2} \mathrm{O}$ & $\mathrm{K}_{2} \mathrm{O}$ & $\mathrm{P}_{2} \mathrm{O}_{5}$ & $\mathrm{CEC}$ & $\mathrm{pH}$ \\
\hline$-0-0-$ & & & & \\
67.8 & 11.4 & 2.3 & 2.06 & 1.56 & - & 0.14 & 0.4 & 103 & 8.7 \\
\hline
\end{tabular}

수준으로 하였다. 요소를 zeolite와 먼저 혼합한 후 토양에 처리하였다. 인산과 칼리는 각각 $112,149 \mathrm{~kg} \mathrm{ha}^{-1}$ 으로 동일 하게 처리하였다 (Table 2). 요소는 2 회 분시, 인산은 용성 인비로 전량 기비, 칼리는 염화칼리로 1 회 분시 하였다. 고 추 정식은 5 월 2 일에 하였으며, 재식거리는 $75 \times 45 \mathrm{~cm}$, 시 험구 면적은 $9.0 \mathrm{~m}^{2}$ 이며, 난괴법 3 반복으로 배치하였다. 시 험에 사용된 zeolite는 $\mathrm{pH} 8.7, \mathrm{CEC} 103 \mathrm{cmol}_{\mathrm{c}} \mathrm{kg}^{-1}$ 이었으며 화학적 조성은 Table 3 과 같다.

토양분석은 국립농업과학원의 토양 및 식물체 분석법 (NIAST, 2000)에 준하여 토양 $\mathrm{pH}$ 는 초자전극법, 유기물함량은 Tyurin 법, 유효인산은 Lancaster법으로 분석하였고, 치환성 양이 온 함량은 $1 \mathrm{M} \mathrm{NH}_{4} \mathrm{OAc}$ 용액 (pH 7.0)으로 추출하여 원자흡 광분석기 (Analyst 400, Perkin Elmer, USA)로 분석하였으 며, 토성은 비중계법으로 측정하였다.

아산화질소의 분석을 위한 시료 채취는 온실가스 연구에 서 일반적으로 쓰이고 있는 챔버법을 이용하였으며 (Kim et al., 2006; Kim et al., 2008; Saggar et al., 2009; Kim et al., 2010; Seo et al., 2012), 시료 채취는 주 2 회 실시하였다. 아산화질소의 분석은 전자포획검출기 $(\mathrm{ECD})$ 를 장착한 가스 크로마토그래프 (Clarus 680, Perkin Elmer, USA)를 이용 하였다. 아산화질소의 배출량은 다음 식을 이용하여 계산하 였다 (Seo et al., 2012).

$$
\mathrm{F}=\rho \cdot \mathrm{V} \cdot \mathrm{A}^{-1} \cdot \Delta \mathrm{c} \cdot \Delta \mathrm{t}^{-1} \cdot 273 \cdot \mathrm{T}^{-1}
$$

여기에서 $\mathrm{F}$ 는 아산화질소 배출량 $\left(\mathrm{mg} \mathrm{m}^{-2} \mathrm{~h}^{-1}\right)$ 이며, $\rho$ 는 아산화질소의 밀도인 $1.96 \mathrm{mg} \mathrm{m}^{-3}$ 이고, $\mathrm{V}$ 와 $\mathrm{A}$ 는 각각 챔버 의 체적 $\left(\mathrm{m}^{3}\right)$ 과 면적 $\left(\mathrm{m}^{2}\right)$ 이며, $\Delta \mathrm{c} \cdot \Delta \mathrm{t}^{-1}$ 는 챔버 내에서의 시 간당 아산화질소 농도의 평균 증가량이고, $\mathrm{T}$ 는 챔버 내 평 균온도 $\left({ }^{\circ} \mathrm{C}\right)$ 에 절대온도 $(273)$ 을 더한 값이다.

토양에 질소질비료 처리 후 초기 $\mathrm{NH}_{3}$ 배출량을 측정하기 위하여 포트실험으로 수행하였다. $\mathrm{NH}_{3}$ 가스는 수정된 closeddynamic air flow system method을 이용하여 분석하였으 며 (Siva et al., 1999), 질소가스를 주입하면서 $\mathrm{NH}_{3}$ 가스를 포집하기 위하여 포트실험을 하였다. 포트실험에 사용된 토 양은 포장실험에 사용된 토양과 동일한 토양이었고, 토양 $1.2 \mathrm{~kg}$ 에 요소 $2.0 \mathrm{~g}$ 처리구, 요소와 zeolite를 혼합 처리구, 무처리로 구분하였고, 요소를 zeolite와 먼저 혼합한 후 토 양에 처리하였다. $\mathrm{NH}_{3}$ 가스 분석은 밀폐된 용기에 pot를 넣 고 질소가스를 $2.4 \mathrm{~L} \mathrm{~min}^{-1}$ 를 주입하면서 $10 \mathrm{~mL}$ boric acid (2 wt\%) 용액을 이용하여 포집하였다. 포집한 암모니아는
$0.01 \mathrm{~N} \mathrm{H}_{2} \mathrm{SO}_{4}$ 로 적정하여 정량하였다.

통계분석은 SAS 프로그램 (Ver. 9.2, SAS, Cary, NC, $\mathrm{USA}$ )을 이용하였으며, $5 \%$ 수준에서 처리간 차이의 통계적 유의성을 검토하였다.

\section{Results and Discussion}

미사식양질 밭토양에 요소와 zeolite 처리후 고추재배기 간 동안 아산화질소 배출 양상은 Fig. 1과 같다. 요소를 처 리한 후 10 일 후부터 배출량이 크게 증가하여 1 일 배출량이 $10 \mathrm{mg} \mathrm{m}^{-2}$ day ${ }^{-1}$ 까지 증가하다 낮아지는 경향을 보였으며, 요소를 웃거름으로 준 다음에 다소 높아지는 양상을 나타내 었다. 요소 단독 처리시에 비해 요소와 zeolite를 혼합 처리 시에 아산화질소 배출량이 크게 증가하여 약 4 개월 동안 누 적된 아산화질소 배출량은 요소 $161 \mathrm{~kg} \mathrm{~N} \mathrm{ha}^{-1}$ 처리구가 $1.164 \mathrm{~kg} \mathrm{~N}_{2} \mathrm{O}-\mathrm{N} \mathrm{ha}^{-1}$ 이었고, $230 \mathrm{~kg} \mathrm{~N} \mathrm{ha}^{-1}$ 처리구는 $1.747 \mathrm{~kg} \mathrm{~N} \mathrm{O}_{2} \mathrm{O}-\mathrm{N} \mathrm{ha}^{-1}$ 이었으며, 요소와 zeolite를 혼합 처 리한 구에서는 $161 \mathrm{~kg} \mathrm{~N} \mathrm{ha}{ }^{-1}$ 처리구가 $1.626 \mathrm{~kg} \mathrm{~N} 2 \mathrm{O}-\mathrm{N}$ $\mathrm{ha}^{-1}, 230 \mathrm{~kg} \mathrm{~N} \mathrm{ha}^{-1}$ 처리구에서는 $2.431 \mathrm{~kg} \mathrm{~N}_{2} \mathrm{O}-\mathrm{N} \mathrm{ha}^{-1}$, 무시용구는 $0.364 \mathrm{~kg} \mathrm{~N} 2 \mathrm{O}-\mathrm{N} \mathrm{ha}^{-1}$ 이었다 (Fig. 2). 요소의 처리량이 증가함에 따라 아산화질소 배출량이 증가하였고, 요소와 zeolite를 혼합처리시 아산화질소 배출량은 요소 단 독처리에 비해 $39 \sim 40 \%$ 정도 높게 나타났다. 아산화질소 배출량은 무기태 질소함량, 토양온도, 토양 중 무기태 질소 함량이 배출에 가장 영향을 크게 미치며 (Kim et al., 2008; Kim et al., 2010), 특히 질소질비료 시용은 농경지로부터

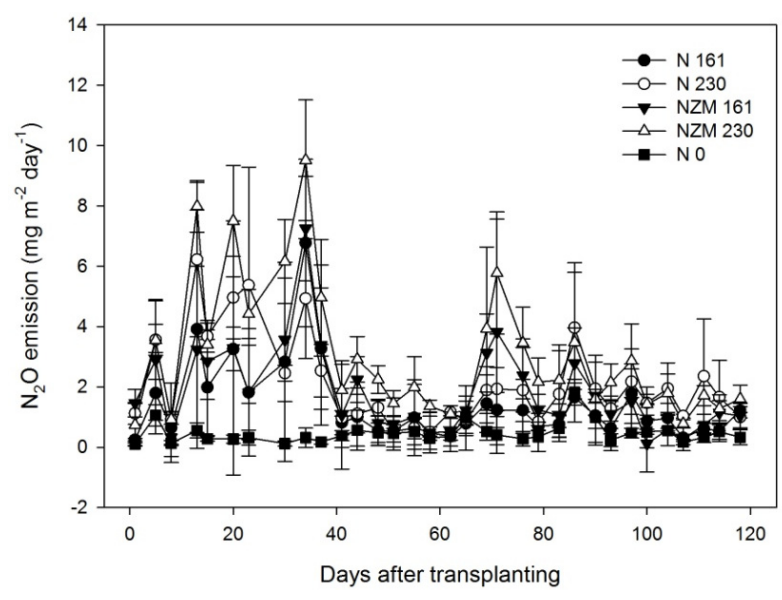

Fig. 1. Time-coursed changes in $\mathrm{N}_{2} \mathrm{O}$ emission during the whole red pepper cultivation. NZM, nitrogen zeolite mixture. 


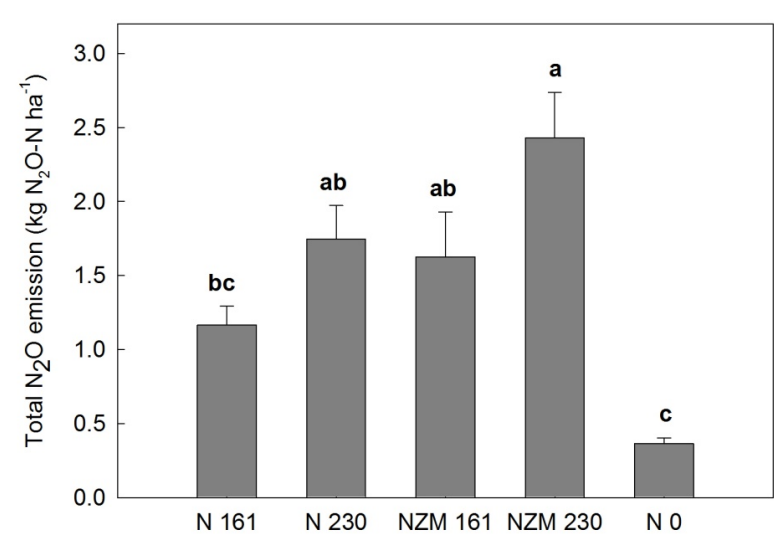

Fig. 2. Total $\mathrm{N}_{2} \mathrm{O}$ emission during the whole red pepper cultivation. NZM, nitrogen zeolite mixture. Emor bars indicate standard deviation. Treatments with same letter are not significantly different at the 0.05 probability level.

대기로 배출되는 아산화질소의 가장 큰 요인으로 작용하고 있다 (Minami, 1997). 토양에 요소를 $200 \mathrm{mg} \mathrm{N} \mathrm{kg}^{-1}$ 시용한 후 zeolite $15 \mathrm{~g} \mathrm{~kg}^{-1}$ 처리시 요소 단독처리에 비해 $\mathrm{NH}_{3}$ 가
스로 휘발되는 양을 유의적으로 감소시켰고 토양중에 $\mathrm{NH}_{4}-\mathrm{N}$ 농도가 더 높았다고 보고하였는데 (He et al., 2002), 본 실 험에서는 zeolite와 요소를 먼저 1:1로 혼합한 후 토양에 $500 \mathrm{~kg} \mathrm{ha}{ }^{-1}$ 처리시 토양중 무기태 질소함량이 높아 아산화 질소 배출량이 증가한 것으로 추측된다.

질소질비료 처리량과 아산화질소 배출량 사이의 상관관 계는 Fig. 3 과 같이 요소 처리량이 증가할수록 아산화배출 량이 크게 증가하여 요소 단독으로 처리시는 $\mathrm{y}=0.0093 \mathrm{x}+$ $0.523\left(\mathrm{R}^{2}=0.982\right)$ 이었고, 요소와 zeolite 혼합처리의 경우는 $\mathrm{y}=0.0141 \mathrm{x}+0.516\left(\mathrm{R}^{2}=0.990\right)$ 으로 높은 회귀관계를 나타내 었다.

요소의 질소이용효율은 $\mathrm{NH}_{3}$ 가스의 휘발에 의한 손실로 인해서 매우 낮으며 (Lara et al., 1997), 질소이용효율을 증 진시키기 위하여 많은 연구가 진행되어 왔다. 토양에 요소 와 zeolite 혼합처리 후 $\mathrm{NH}_{3}$ 배출량을 측정한 결과는 Fig. 4 와 같다. 토양 $1.2 \mathrm{~kg}$ 에 요소 $2 \mathrm{~g}$ 처리는 토심 $15 \mathrm{~cm}$, 용적 밀도 1.2 로 적용하였을 때 $1,380 \mathrm{~kg} \mathrm{~N} \mathrm{ha}^{-1}$ 의 수준으로 많은 양의 질소가 시용되었다. $\mathrm{NH}_{3}$ 휘발량은 요소비료 처리 후 1

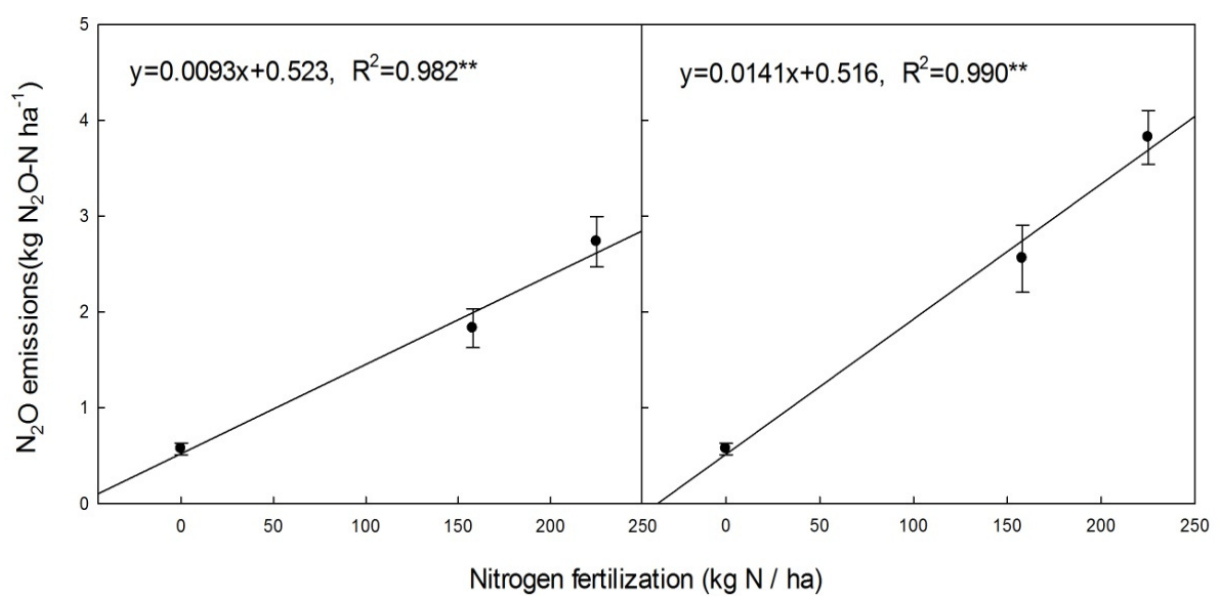

Fig. 3. Correlation between $\mathrm{N}_{2} \mathrm{O}$ emission and the mixture of nitrogen and zeolite in upland soil during red pepper. (a)nitrogen only, (b)nitrogen zeolite mixture.
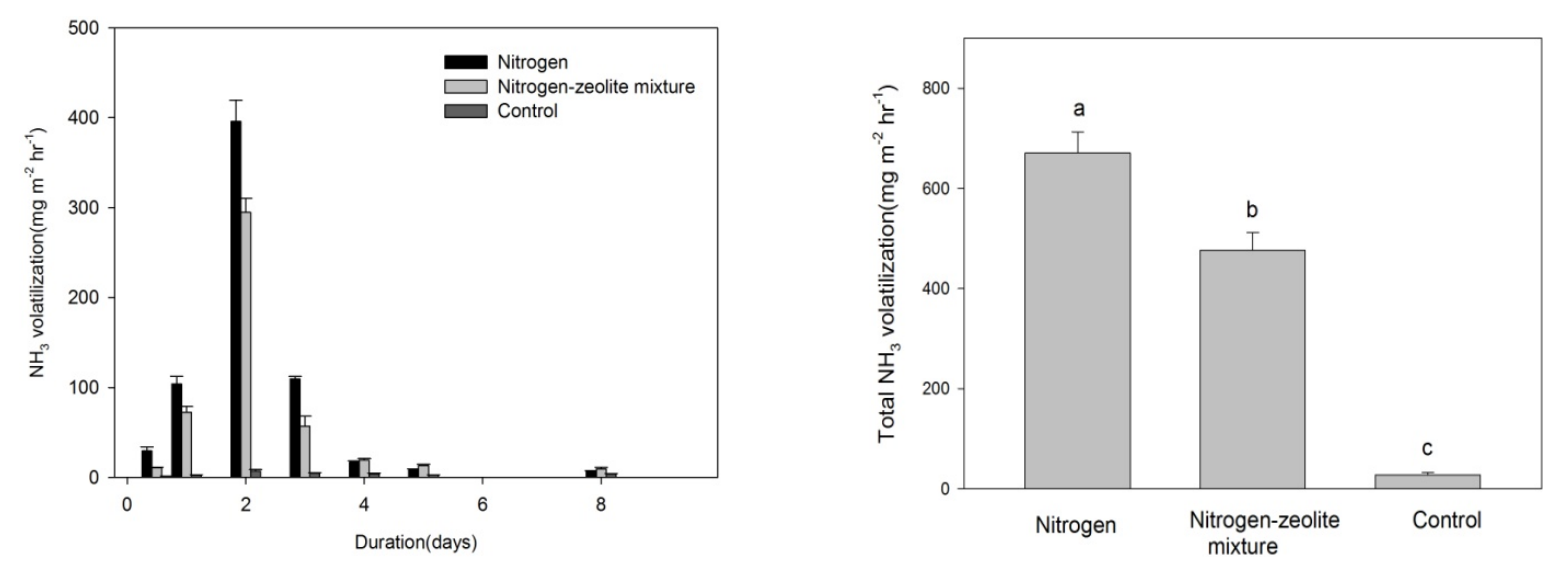

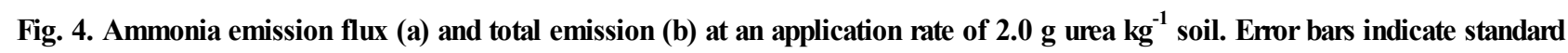
deviation. Treatments with same letter are not significantly different at the 0.05 probability level. 
일부터 급격하게 증가하여 2일에 최대발생량을 나타내었고 그 이후 감소하는 경향을 나타내었다. 요소 단독처리에 비 하여 요소와 zeolite 혼합처리에서 $\mathrm{NH}_{3}$ 휘발량이 $30 \%$ 감소 하였다.

농경지 토양에서 대기로 배출되는 아산화질소 중에 $81 \%$ 가 질소질 비료에 의해 배출되며 (Iserman, 1994), 토양중 무기태 질소 가운데 질산태질소의 상승이 아산화질소 배출 량을 증가시킨다고 하였다 (Hellebrand et al., 2008). 이러 한 화학비료 시용은 아산화질소 직접 배출 원인이 되기도 하지만, $\mathrm{NH}_{3}$ 나 $\mathrm{NO}_{x}$ 의 형태로 대기 중으로 휘발되거나, $\mathrm{NO}_{3}^{-}$ 형태로 수계로 유출되는 간접배출의 원인이 되기도 한다 (Cole et al., 1997). Zeolite는 대략 100 $200 \mathrm{cmol}_{\mathrm{c}} \mathrm{kg}^{-1}$ 의 높은 $\mathrm{CEC}$ 를 가지며, 토양에 처리할 경우 질소 이용효율을 극대 화시킬 뿐만 아니라 토양산도 교정으로 유효양분이 증대되 어 작물의 생산량이 높아지며, 질소의 유실을 방지하여 환 경오염을 줄이는 것으로 보고하였다 (Barbarick and Pirela, 1984; Ippolito et al., 2011).

본 연구에서는 zeolite와 요소의 혼합처리는 초기 암모니 아 가스의 휘발량을 줄이는 긍정적인 효과가 있어 질소의 양분이용효율을 증진시킬 수 있을 것으로 판단되었지만, zeolite 처리에 따른 아산화질소 배출을 증가하는 부정적인 결과를 나타내어 zeolite 처리시 토양관리 방안에 대한 추가 적인 연구가 필요할 것으로 판단되었다.

\section{Conclusions}

미사식양질 밭토양에서의 요소와 zeolite 혼합 처리시 아 산화질소와 암모니아 배출량에 미치는 영향을 평가하였다. 고추 재배기간동안 요소 처리량이 증가할수록 아산화질소 배출량이 증가하였고 요소와 zeolite 혼합처리구가 요소 단 독 처리구에 비해 아산화질소 배출량이 $39 \sim 40 \%$ 증가하였 다. 요소 처리량과 아산화질소 배출량은 고도의 정의상관관 계를 나타내었다. 요소 단독처리에 비하여 요소와 zeolite 혼합처리에서 $\mathrm{NH}_{3}$ 휘발량이 $30 \%$ 감소하였다. 따라서, zeolite 와 요소의 혼합처리는 초기 $\mathrm{NH}_{3}$ 휘발량을 줄이는 긍정적인 효과가 있었지만, 밭토양 온실가스인 아산화질소 배출을 증 가시키는 부정적인 결과를 나타내었다.

\section{References}

Barbarick, K.A. and H.J. Pirela. 1984. Agronomic and horticultural uses of natural zeolites: A review. pp. 93-103. In: W.G. Pond, and F.A. Mumption (eds.). Zeo-agriculture: Uses of natural zeolite in agriculture and aquaculture. Westview Press, Boulder, CO.

Clifton, R.A. 1987. Natural and synthetic zeolites. U.S. Bureau of Mines Information Circular 9140, p. 21.
Cole, C.V., J. Duxbury, J. Freney, O. Heinemeyer, A. Mosier, A. K. Paustian, M. Rosenberg, N. Sampson, D. Sauerbeck, and Q. Zhao. 1997. Global estimates of potential mitigation of greenhouse gas emissions by agriculture. Nutr. Cycl. Agroecosyst. 52: 221-228.

Duxbury, J.M., L.A. Haper, and A.R. Mosier. 1993. Contributions of agroecosystems to global climate change. p. 1-18. In: D.E. Rolston et al. (ed.) Agricultural ecosystem effects on trace gases and global climate change, ASA special Publication 55. ASA, CSSA and SSSA. Madison. USA.

He, Z.L., D.V. Calvert, A.K. Alva, Y.C. Li, and D.J. Banks. 2002. Clinoptilolite zeolite and cellulose amendments to reduce ammonia volatilization in a calcareous sandy soil. Plant Soil 247: 253-260.

Hellebrand, H.J., V. Scholz, and J. Kern. 2008. Fertilizer induced nitrous oxide emissions during energy crop cultivation on loamy sand soils. Atmospheric Environment. 42:8403-8411.

Ippolito, J.A., D.D. Tarkalson, and G.A. Lehrsch. 2011. Zeolite soil application method affects inorganic nitrogen, moisture, and corn growth. Soil Sci. 176(3):136-142.

Iserman, K. 1994. Agriculture's share in the emissions of trace gases affecting the climate and some cause oriented proposal for reducing this share, Environ. Pollut. 83:95-111.

Kim, G.Y., B.H. Song, B.K. Hyun, K.M. Shim, J.T. Lee, J.S. Lee, W.I. Kim, and J.D. Shin. 2006. Predicting $\mathrm{N}_{2} \mathrm{O}$ emission from upland cultivated with pepper through related soil parameters. Korean J. Soil Sci. Fert. 39:253-258.

Kim, G.Y., B.H. Song, K.A. Roh, S.Y. Hong, B.G. Ko, K.M. Shim, and K.H. So. 2008. Evaluation of greenhouse gases emissions according to changes of soil water content, soil temperature and mineral $\mathrm{N}$ with different soil texture in pepper cultivation. Korean J. Soil Sci. Fert. 41:399-407.

Kim, G.Y., K.H. So, H.C. Jeong, K.M. Shim, S.B. Lee, and D.B. Lee. 2010. Assessment of greenhouse gases emissions using global warming potential in upland soil during pepper cultivation. Korean J. Soil Sci. Fert. 43:886-891.

Lara Cabezas W.A.R., G.H. Korndorfer, and S.A. Motta. 1997. $\mathrm{NH}_{3}-\mathrm{N}$ volatilization in corn crop: II - Evaluation of solid and fluid sources under no-tillage and conventional system. Revista Brasileira Ciência do Solo. 21:489-496.

Minami, K. 1997. Atmospheric methane and nitrous oxide: sources, sinks and strategies for reducing agricultural emissions. Nutr. Cycl. Agroecosyst. 49:203-211.

NIAST (National Institute of Agricultural Science and Technology). 2000. Analytical methods of soil and plant. RDA, Suwon, Korea.

NIAST (National Institute of Agricultural Science and Technology). 2010. Fertilizer recommendation for crops. RDA, Suwon, Korea.

NIR. 2012. National greenhouse gas inventory report of Korea. Greenhouse Gas Inventory and Research Center of Korea.

Parham, W.E. 1989. Natural zeolites: some potential agricultural 
applications for developing countries: Natural Resources Forum, May, 107-115.

Powlson, D. S., T. M. Addiscott, N. Benjamin, K.G. Cassman, T.M. de Kok, H.V. Grinsven, J.L. Lhirondel, A.A. Avery, and C.V. Kessel. 2008. When does nitrate become a risk for humans. J. Environ. Qual. 37:291-295.

Saggar, S., J. Luo, D.L. Giltrap, and M. Maddena. 2009. Nitrous oxide emissions from temperate grasslands: Processes, measurements, modelling and mitigation. pp. 1-66. In Sheldon and Barnhart (eds.): Nitrous oxide emissions research progress. Nova Science Publishers, Inc., New York.

Seo, Y.H., S.W. Kim, S.C. Choi, B.C. Jeong, and Y.S. Jung.
2012. Nitrous oxide emission from livestock compost applied arable land in Gangwon-do. Korean J. Soil Sci. Fert. 45:25-29. Shin, Y.K., J.W. Ahn, M.H. Koh, and J.C. Shim. 2003. Emissions of greenhouse gases from upland rice and soybean. Korean J. Soil Sci. Fert. 36:256-262.

Siva, K.B., H. Aminuddin, M.H.A. Husni, and A.R. Manas. 1999, Ammonia volatilization from urea as affected by tropical-based palm oil palm effluent (pome) and peat. Soil Sci. Plant Anal. 30:785-804.

Stehfest, E. 2008. Modelling of global crop production and resulting $\mathrm{N}_{2} \mathrm{O}$ emissions. VDM Verlag Dr. Müller, Saarbrüken, Germany. 